\title{
Assessment of Knowledge, Self-care Practice, and Associated Factors Among Hypertensive Patients the Public Hospital of Addis Ababa Ethiopia 2016 G.C.
}

\author{
Sindew Mahmud Ahmed ${ }^{1}$, Melaku Belaye Teferi ${ }^{2}$ \\ ${ }^{1}$ Department of Nursing, College of Medical and Health Sciences, Kotebe Metropolitan University, Addis Ababa, Ethiopia \\ ${ }^{2}$ Department of Surgery, Turenesh Bejing Hospital, Addis Ababa, Ethiopia
}

Email address:

hayatlove2005@gmail.com (S. M. Ahmed), Belay.melaku@yahoo.com (M. B. Teferi)

To cite this article:

Sindew Mahmud Ahmed, Melaku Belaye Teferi. Assessment of Knowledge, Self-care Practice, and Associated Factors Among Hypertensive Patients the Public Hospital of Addis Ababa Ethiopia 2016 G.C. International Journal of Cardiovascular and Thoracic Surgery.

Vol. 6, No. 2, 2020, pp. 28-37. doi: 10.11648/j.ijcts.20200602.13

Received: February 18, 2020; Accepted: April 14, 2020; Published: June 29, 2020

\begin{abstract}
Background: Patients with hypertension are a high risk of cardiovascular disease. An increase of $10 \mathrm{mmHg}$ (more than normal) in diastolic blood pressure leads to a relatively increased risk of stroke and cardiovascular disease by $37 \%$. Moreover, hypertension may impair vision. The symptoms range from blurred vision to blindness. A lack of knowledge about hypertension negatively influences patients' awareness and behaviors and is a major obstacle in controlling hypertension. The general objective of the study was to assess the overall level of knowledge, self-care practices, and its associated factors among hypertensive patients in adult cardiac and renal referral clinics in public hospitals Addis Ababa city Administration Addis Ababa Ethiopia. Methods: An institutional-based cross-sectional study was conducted in public health hospitals. The final sample size was 384, which was proportionally allocated to each of the institutions and systematic random sampling was used to select study units that were part of the study. Results: The results of the study showed that (43.6\%) of the study participants had good knowledge about hypertensive self-care. A strong association was observed between knowledge about hypertension and educational status, family history of hypertension, place of residence; and occupational status of the study participants. About (51.5\%) of the study participants had good self-care practices towards hypertension. However, there was a significant association between self-care practices, place of residence and educational status of the study participants. Study participants who had secondary and above educational status had good self-care practice than participants had no formal education. Conclusion: Despite the important role of knowledge and self-care practices in the management of hypertension is recognized to be useful and effective in achieving hypertension control and preventing its complication. The findings of this study confirmes that self-care practices was accomplished as recommended by the majority of respondents, but knowledge was more problematic.
\end{abstract}

Keywords: Hypertension, Knowledge, Self-care Practice and Factors

\section{Background}

Hypertension is defined as an increase in blood pressure greater than or equal to $160 / 95 \mathrm{mmHg}$ according to the World Health Organization [1]. It is categorized as "primary hypertension", which means high blood pressure with no obvious underlying medical cause and accounts about 90$95 \%$. Or. The remaining $5-10 \%$ of cases (secondary hypertension) are caused by conditions that affect the kidneys, arteries, heart, or endocrine system [3]. A lack of knowledge about hypertension adversely influences patients' awareness and behaviors, and is a major challenge in controlling hypertension [8]. People with hypertension can prevent the squeals of the disease and prevent the possible complications caused by raised in blood pressure by taking care of themselves. Self-care refers to learned, conscious, and purposeful practices, which people do for themselves, their children and their families to stay healthy and maintain their proper health, both mentally and physically, meet their social and psychological needs, and prevent illness or accident. 
Self-care is not a substitute but a supplement, that determine how to apply professional and organizational care [10]. The self-care practices for prevention of complications of hypertension includes not taking salty foods. No smoking, abstained from drinking any alcohol, and being adherent to antihypertension medication [11]. Self-care practices introduced in healthy behavior are vital in both the prevention, and management of hypertension. But barriers to hypertension self-care, and control are well studied and exist at the patient, provider, and health institution levels. These barriers include lack of knowledge about the seriousness of untreated hypertension and the benefits of controlling hypertension, unemployment, alcohol, and illicit drug use, cost of care and medications, drug side effects and complexity of the regimen [12].

A recent report on the benefits of restoring normal blood pressure at the stage of prehypertension in a developed area. However, in a rural area, self- care intervention would be a more feasible strategy to prevent hypertension in persons at risk. In the rular community, the most prevalent risk behavior was smoking, followed by alcohol consumption [13]. Therefore, knowledge about the patientse condition and information with regard to their self-care ability is vital, as patients themselves reported that knowledge about their condition and its management will be important factors in their self- care behaviors. For those living with hypertension, self-management through self-care will facilitate well-being, decrease the effects of the disease, and limit disease progression [14]. Recent reports have revealed that BP education plays a significant role in increasing hypertension knowledge. Patients who were aware that hypertension led to reductions in life expectancy had a higher compliance level with medication use and follow-up visits than patients without this awareness [19].

Studies have investigated that hypertensive patients should have good knowledge and self-care practices regarding salt restriction, adherence to medication, engaging regular physical exercise, and refrain from smoking to control their blood pressure [12]. From the above it has been observed that knowledge and self-care practices, including inability to modify their diet, more salt intake, inadequate maintenance of a healthy weight, smoking, and lack of getting regular exercise, is very much common in hypertensive patients in the world especially in developing countries. Most people have inadequate knowledge and self-care about the seriousness of hypertension. Bearing in mind this situation and the lack of study on this area, it is necessary to assess the overall level of knowledge, self-care practices, and its associated factors with treatment among patients with hypertension. The general objective of this study was to assess the level of knowledge, self-care practices, and its associated factors among hypertensive patients the public hospital of Addis Ababa Ethiopia 2016 G.C.

Objectives

General objectives

To assess knowledge, self-care practices, and its associated factors among hypertensive patients the public hospital of
Addis Ababa Ethiopia 2016 G.C.

Specific objectives

To assess Knowledge, towards self-care practices, and its associated factors among hypertensive patients at public hospital of Addis Ababa Ethiopia 2016 G.C.

To assess self-care practices for hypertension and its associated factors among hypertensive patients at public hospital of Addis Ababa Ethiopia 2016 G.C.

\section{Methods}

\subsection{Study Area and Design}

An institutional-based cross-sectional study was conducted in the public hospitals of Addis Ababa. The sample size of study participants that was recruited in the research was calculated using the single population proportion formula. The final sample was 384 .

\subsection{Study Variables}

\subsubsection{Independent Variables}

Sociodemographic characteristics,

Age at hypertensive onset,

Duration of disease,

Family history of hypertension,

Complications,

Source of information,

Income,

Risk factors for hypertension.

\subsubsection{Dependent Variable}

Knowledge of hypertension.

Self-care practices of the patients.

\subsection{Operational Definitions}

Knowledge:, An idea by which hypertensive patients had about the definition, risk factors, signs and symptoms, effect, diagnostic methods, and treatment of hypertension.

Self-Care-Practice: An activity conducted by hypertensive patient towards their illness includes, diet, exercise, medication adherence, self-blood pressure measurement.

Good knowledge: Knowledge score that fell above mean of 32 knowledge questions.

Poor knowledge: Knowledge score below mean of 32 knowledge questions.

Physical activity: The minimum physical activity level was determined as 30 minutes, moderate activity for at least 3 days per week.

Good practice: Practice score above the mean of 21 practice questions.

Poor practice: Practice score below the mean of 21 practice questions.

\subsection{Data Collection Tool and Procedures}

Interviewer-administered structured questionnaires were employed to collect data. Knowledge was assessed by requesting thirty-one questions. The mean score was used to 
categorize study subjects as having good knowledge or poor knowledge about hypertension. Self-care practice about hypertension was also assessed by requesting respondents to answer twenty questions. Accordingly, the sum value less than the mean was categorized as self-care practice and the value greater than or equal to the mean was categorized as good self-care practice.

\subsection{Data Processing and Analysis}

Data were checked, cleaned, and entered into Epidata, and imported to SPSS version 20.0 software for analysis. Incomplete and inconsistent data were excluded from the analysis. Descriptive statistics were used to describe the sample. The results of the descriptive statistics are expressed as percentages and frequencies. Associations between independent variables and dependent variables were analyzed first using bivariate analysis to identify factors that are significantly associated with the outcome variable. The magnitude of the association between the different independent variables in relation to dependent was measured using odds ratios and 95\% confidence interval (CI), and $\mathrm{P}$ values below 0.05 were considered statistically significant.

\subsection{Ethical Consideration}

Ethical clearance and an official letter were obtained from the Research and Ethics Committee of AAU to the selected public health hospitals. Latter was written for respective hospitals, and permission was obtained from respective hospitals. Verbal and written consent was obtained for willingness of patients to participate.

\section{Results}

\subsection{Socio-demographic Characteristics of Respondents}

The mean age of respondents was $57 \pm 13$, most of the respondents $205(55.6 \%)$ were within $41-60$ age group. The majority of the respondents $195(52.8 \%)$ were civil servants. A large proportion of the study subjects 188 (50.9\%) had no family history of the disease. The majority $186(50.4 \%)$ of the respondents get health information from a health professional (Table 1).

Table 1. Socio-demographic characteristics of respondents in public hospitals, of Addis Ababa city administration central Ethiopia, April 2016.

\begin{tabular}{lll}
\hline Variable & Frequency & Percent \\
\hline Sex Male & 186 & 50.4 \\
Female & 183 & 49.6 \\
Occupation & & \\
Farmer & 29 & 7.9 \\
House wife & 48 & 13.0 \\
Merchant & 96 & 26.0 \\
Civil servant & 196 & 53.1 \\
Age $<40$ & 30 & 8.1 \\
$41-60$ & 205 & 55.6 \\
$61-80$ & 121 & 32.8 \\
$81-99$ & 13 & 3.5 \\
\hline
\end{tabular}

\begin{tabular}{lll}
\hline Variable & Frequency & Percent \\
\hline Place of residence & & \\
Rular & 239 & 64.8 \\
Urban & 129 & 35.2 \\
Educational status & & \\
Illiterate & 58 & 15.7 \\
Primary & 118 & 32.0 \\
Secondary and above & 193 & 52.3 \\
Marital status & & \\
Single & 31 & 8.4 \\
Married & 243 & 65.9 \\
Divorced & 33 & 8.9 \\
Widowed & 62 & 16.8 \\
Income & & \\
$<500$ & 69 & 18.7 \\
500-1000 & 122 & 33.1 \\
$>1000$ & 178 & 48.2 \\
Habit & & \\
Smoking & 15 & 4.1 \\
Alcohol & 51 & 13.8 \\
None & 303 & 82.1 \\
family history of hypertension & & \\
Yes & 181 & 49.1 \\
No & 188 & 50.9 \\
Source of health info & & \\
Family member & 69 & 50.9 \\
Mass media & 114 & \\
Health professional & 186 & \\
\hline & & \\
\hline
\end{tabular}

\subsection{Knowledge of Hypertensive Patients with Hypertension}

The total mean score for knowledge was $(15.0325 \pm$ (SD $2.98)$ ). One hundred sixty-one (43.6\%) respondents scored above the mean on the 32 questions. The remaining two hundred eight $(56.4 \%)$ of the study respondents scored below the mean. The maximum score 28 of 32 knowledge questions and the minimum score was 5 with a range of 23 of 32 questions. (Tables 2, 3, 5 and figure 1)

Table 2. Knowledge about the risk factors, signs and symptoms of hypertension and rest required for hypertensive patients among hypertensive patients in public hospitals of Addis Ababa city Administration Addis Ababa Ethiopia April 2016.

\begin{tabular}{llll}
\hline Variable & Response & Frequency & Percent \\
\hline \multirow{2}{*}{ Risk factors for } & Stress & 268 & 43.2 \\
hypertension & Age & 181 & 29.1 \\
Sign and symptom of hypertension & 172 & 27.7 \\
Headache & Yes & & \\
& No & 339 & 92.1 \\
Dizziness & Yes & 29 & 7.9 \\
& No & 75 & 20.4 \\
Nausea & Yes & 293 & 79.6 \\
& No & 39 & 10.6 \\
Don't know & Yes & 329 & 89.4 \\
& No & 29 & 7.9 \\
& Complete bed rest & 340 & 92.1 \\
How often do you & Refrain from activity & 137 & 16.5 \\
rest per day & Restricted from activity & 127 & 36.9 \\
& No need of rest & 19 & 34.4 \\
& Don't known & 22 & 5 \\
\hline
\end{tabular}


Table 3. Knowledge about prompt diagnostic test and lifestyle modification to control hypertension among hypertensive patients in public hospitals of Addis Ababa City Administration April 2016 Addis Ababa Ethiopia. $\{n=369\}$.

\begin{tabular}{|c|c|c|c|}
\hline Variable & Response & Frequency & Percent \\
\hline \multirow{5}{*}{$\begin{array}{l}\text { What is the prompt diagnostic study of } \\
\text { hypertension? }\end{array}$} & Blood test & 16 & 4.3 \\
\hline & Urine test & 6 & 1.6 \\
\hline & Chest x-ray & 8 & 2.2 \\
\hline & BP measurement & 331 & 89.7 \\
\hline & Don't know & 8 & 2.2 \\
\hline \multirow{5}{*}{ Nutritional therapy for hypertension } & Water restriction & 19 & 5.1 \\
\hline & Decrease salt intake & 315 & 85.4 \\
\hline & Increase salt intake & 6 & 1.6 \\
\hline & Decrease calories food & 14 & 3.8 \\
\hline & Don’t know & 15 & 4.1 \\
\hline \multirow{5}{*}{$\begin{array}{l}\text { How can you maintain normal body } \\
\text { weight? }\end{array}$} & Over eating & 9 & 2.4 \\
\hline & Eating fatty foods & 13 & 3.5 \\
\hline & Regular exercise and optimal calorie & 319 & 86.4 \\
\hline & Calorie restriction & 16 & 4.3 \\
\hline & Don’t know & 12 & 3.3 \\
\hline \multirow{3}{*}{ Best methods to control hypertension? } & Drug therapy & 304 & 32.1 \\
\hline & Diet therapy & 337 & 35.6 \\
\hline & Regular exercise & 309 & 32.3 \\
\hline \multirow{4}{*}{$\begin{array}{l}\text { Foods to be avoid by hypertensive } \\
\text { patients? }\end{array}$} & Salty and salt rich food & 339 & 82.5 \\
\hline & Spice food & 42 & 10.2 \\
\hline & Pulses & 17 & 4.1 \\
\hline & Vegetable & 13 & 3.2 \\
\hline \multirow{5}{*}{$\begin{array}{l}\text { At what time, hypertensive medications } \\
\text { should be taken? }\end{array}$} & under stress situation & 21 & 5.7 \\
\hline & life long & 309 & 83.7 \\
\hline & Activity required physical excretion & 2 & 0.5 \\
\hline & When ever feel bad & 25 & 6.8 \\
\hline & Don't know & 12 & 3.3 \\
\hline \multirow{5}{*}{$\begin{array}{l}\text { How does hypertensive patient should } \\
\text { take medication? }\end{array}$} & As information got from other hypertensive patient & 2 & .5 \\
\hline & As info got from book and journal & 13 & 3.5 \\
\hline & As long term prescription for illness & 23 & 6.2 \\
\hline & As current prescription & 326 & 88.3 \\
\hline & Don’t know & 5 & 1.4 \\
\hline \multirow{5}{*}{ Best measures to reduce stress? } & Involving strenuous exercise & 14 & 3.8 \\
\hline & Yoga and medication & 186 & 50.4 \\
\hline & Sleep medication & 59 & 16 \\
\hline & Watching television & 61 & 16.5 \\
\hline & Don’t know & 49 & 13.3 \\
\hline \multirow{5}{*}{ Exercise hypertension? for } & Jogging and walking & 335 & 90.8 \\
\hline & Weight lifting & 8 & 2.2 \\
\hline & Driving & 4 & 1.1 \\
\hline & Dancing & 7 & 1.9 \\
\hline & Don't know & 15 & 4.1 \\
\hline
\end{tabular}

Table 4. Knowledge about prompt diagnostic test and lifestyle modification to control hypertension among hypertensive patients in public hospitals of Addis Ababa City Administration April 2016 Addis Ababa Ethiopia. $\{n=369\}$.

\begin{tabular}{|c|c|c|c|}
\hline Variable & Response & Frequency & Percent \\
\hline \multirow{5}{*}{$\begin{array}{l}\text { How can you maintain Normal body } \\
\text { weight? }\end{array}$} & Eating too much & 9 & 2.4 \\
\hline & Eating fatty foods & 13 & 3.5 \\
\hline & Regular exercise & 319 & 86.4 \\
\hline & Restrict calorie & 16 & 4.3 \\
\hline & Don’t know & 12 & 3.3 \\
\hline \multirow{4}{*}{ How long should a person exercise daily } & $<30$ minutes & 218 & 59.1 \\
\hline & 30-60 minutes & 51 & 13.8 \\
\hline & $>60$ minutes & 10 & 2.7 \\
\hline & Don’t know & 90 & 24.4 \\
\hline \multirow{5}{*}{ Salt rich food? } & Pickles & 118 & 32 \\
\hline & Milk & 19 & 5.1 \\
\hline & Vegetables & 7 & 1.9 \\
\hline & Rice & 10 & 2.7 \\
\hline & Don't know & 214 & 58 \\
\hline
\end{tabular}




\begin{tabular}{|c|c|c|c|}
\hline Variable & Response & Frequency & Percent \\
\hline \multirow{2}{*}{ Do you think HPN occur genetically? } & Yes & 242 & 65.3 \\
\hline & No & 127 & 34.7 \\
\hline \multirow{2}{*}{ Over all knowledge score } & Poor knowledge & 208 & 56.4 \\
\hline & Good knowledge & 161 & 43.6 \\
\hline
\end{tabular}

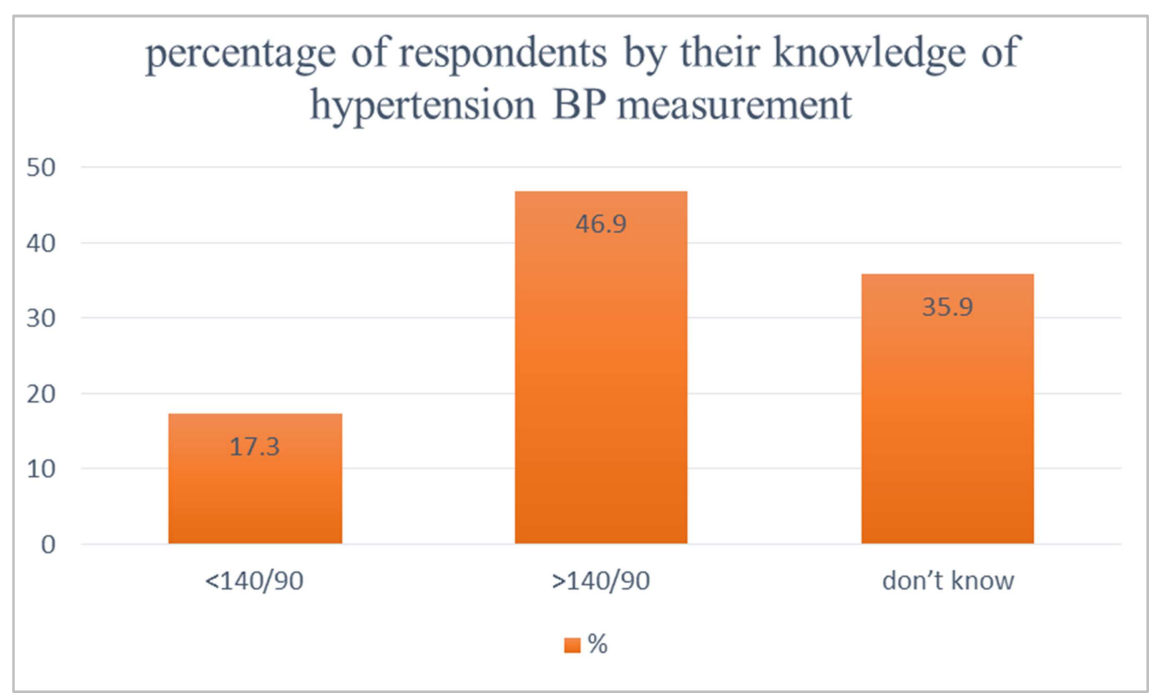

Figure 1. Knowledge of respondents about the definition of hypertension in public hospitals of Addis Ababa City Administration Addis Ababa Ethiopia 2016 G C.

\subsection{Self-care Practices of Hypertensive Patients with Hypertension}

The overall self-care practice is described using the mean score of self -care. A total of 21 questions were asked to assess the overall self-care practices of the study subjects. About 190 (51.5\%) of study participants scored above 8.6070 with a standard deviation of 2.6146. The maximum score was 14 and the minimum score of 3 , and the range was 11 . (Tables 5 and 6 ).

Table 5. Self-care practice of study participants in public hospitals of Addis Ababa City Administration April 2016 Addis Ababa Ethiopia.

\begin{tabular}{|c|c|c|c|}
\hline Variables & Response & Frequency & Percent \\
\hline \multirow{2}{*}{ Ever checked your BP? } & Yes & 351 & 95.1 \\
\hline & No & 18 & 4.9 \\
\hline \multirow{3}{*}{ If yes when? } & In this month & 234 & 66.7 \\
\hline & last six month & 95 & 27.1 \\
\hline & six months ago & 22 & 6.3 \\
\hline \multirow{2}{*}{ Do you drink? } & Yes & 105 & 28.5 \\
\hline & No & 264 & 71.5 \\
\hline \multirow{4}{*}{ If yes, how much? } & $<1$ drink/week & 336 & 33.6 \\
\hline & 1-3 drink/week & 55 & 51.4 \\
\hline & 4-6 drink/week & 15 & 14 \\
\hline & $>=7$ drink/week & 1 & .9 \\
\hline \multirow{5}{*}{ How often do you add salt to your food? } & Never & 174 & 47.2 \\
\hline & Rarely & 127 & 34.4 \\
\hline & Sometimes & 39 & 10.6 \\
\hline & Often & 17 & 4.6 \\
\hline & Always & 12 & 3.3 \\
\hline \multirow{6}{*}{$\begin{array}{l}\text { Which practice do you carry out to } \\
\text { control your BP? }\end{array}$} & Medication and exercise & 140 & 37. \\
\hline & Less stress & 77 & 20. \\
\hline & Quit smoking & 84 & 22.8 \\
\hline & Reduce salt & 29 & 7.9 \\
\hline & DASH & 21 & 5.7 \\
\hline & Losing weight & 18 & 4.9 \\
\hline \multirow{2}{*}{ Do you check your cholesterol? } & Yes & 133 & 36 \\
\hline & No & 236 & 64 \\
\hline \multirow{5}{*}{ If yes, how often? } & Once in life & 45 & 33.8 \\
\hline & Monthly & 10 & 7.5 \\
\hline & Every 3 month & 22 & 16.5 \\
\hline & Every six month & 35 & 26.3 \\
\hline & More than never & 21 & 15.8 \\
\hline
\end{tabular}




\begin{tabular}{|c|c|c|c|}
\hline Variables & Response & Frequency & Percent \\
\hline \multirow{2}{*}{ Do you care about the food you take? } & Yes & 323 & 87.5 \\
\hline & No & 46 & 12.5 \\
\hline \multirow{3}{*}{ Do you perform the physical exercise? } & Yes & 204 & 55.7 \\
\hline & No & 165 & 44.3 \\
\hline & 3 times/week & 40 & 19.5 \\
\hline \multirow[t]{2}{*}{ If yes, how often do you exercise? } & $<3$ times per/we & 156 & 76.1 \\
\hline & $>3$ times/we & 9 & 4.4 \\
\hline \multirow{4}{*}{ For how long do you exercise? } & $<15$ minutes & 33 & 16 \\
\hline & $15-30$ minutes & 74 & 35.9 \\
\hline & 30-60 minutes & 80 & 38.8 \\
\hline & $>60$ minutes & 17 & 9.2 \\
\hline
\end{tabular}

Table 6. Self-care practice of study participants in public hospitals of Addis Ababa City Administration April 2016 Addis Ababa Ethiopia.

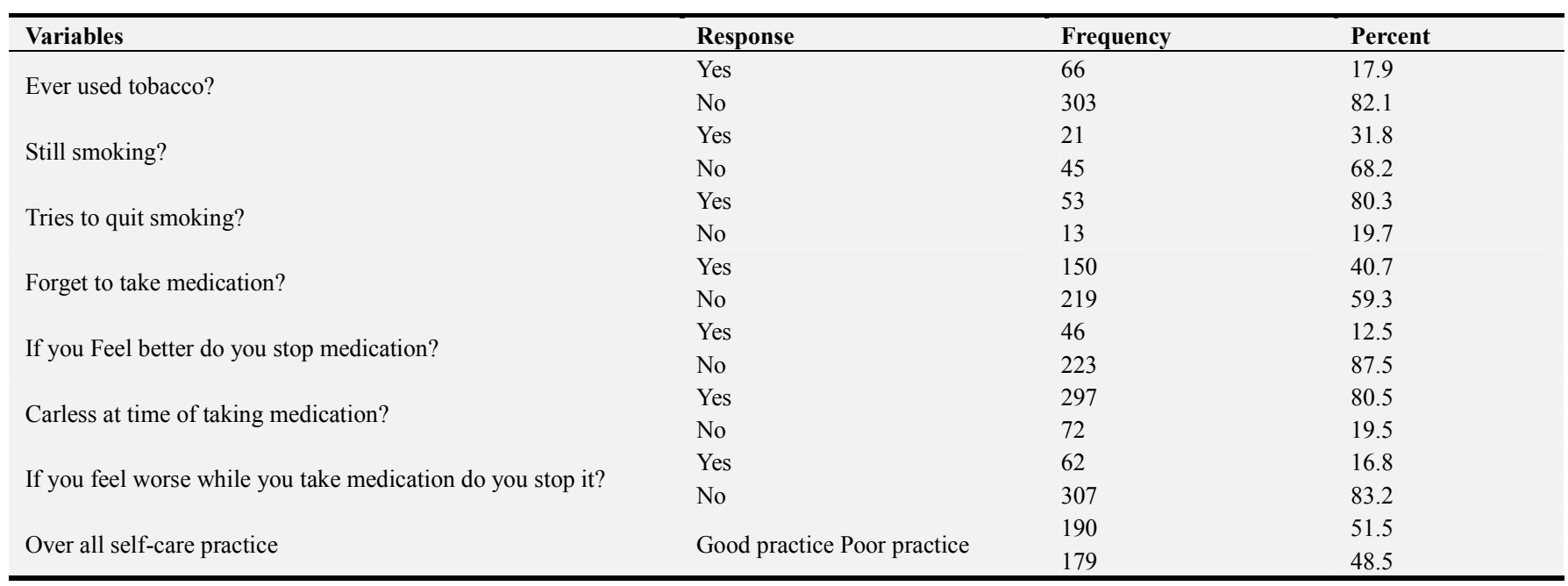

\subsection{Factors Influencing Knowledge About Hypertension}

Bivariate analysis showed significant associations between knowledge and educational status, monthly income, habits, sex, marital status, place of residence, the source of health information, family history of hypertension, self-care practices, and age of the respondents. In multiple logistic analyses, the only family history of hypertension, educational status, occupation, and place of residence of the respondents maintained a significant association with knowledge of hypertension. The majority of hypertensive patients who had a family history had good knowledge about hypertension definition, risk factors, signs, and symptoms of hypertension, methods to control hypertension, diet, and drug therapy. In this study, knowledge about hypertension was significantly associated with family history of hypertension, place of residence, educational status, and occupational status of the study participants.

Study participants who had no family history of hypertension two times less likely to have good knowledge compared with those who had a history of hypertension. $\{(p=0.004$, AOR $(95 \% \mathrm{CI}), 2.052(1.254-3.360)\}$. In addition, those who live in rural $73 \%$ less likely to have good knowledge compared with those living in urban. $\{(\mathrm{p}=0.035$, AOR (95\%CI) $0.271(0.0800 .911)\}$. Respondents who had no formal education and primary education educational level four and three times less likely to have good knowledge as compared with those with secondary and above education $\{(\mathrm{p}=0.002,0.021$, AOR $(95 \% \mathrm{CI}) 3.924$ (1.636$9.412)\}$ and 2.848 (1.173-6.914) $\}$. There was a significant association between being a merchant and knowledge about hypertension. Statically merchants three times less likely to have good knowledge compared with civil servants $\{(p=0.021$, AOR, $(95 \% \mathrm{CI}) 2.848$ (1.173-6.914). table 7

Table 7. Factors affecting knowledge about hypertension among hypertensive patients in public hospitals of Addis Ababa City administration April 2016 Addis Ababa Ethiopia.

\begin{tabular}{|c|c|c|c|c|c|c|}
\hline \multirow{2}{*}{ Variable } & \multirow{2}{*}{ Response } & \multicolumn{2}{|l|}{ Knowledge } & \multirow{2}{*}{ COR $(95 \% \mathrm{CI})$} & \multirow{2}{*}{ AOR (95\%CI) } & \multirow{2}{*}{$P$ value } \\
\hline & & Good & Poor & & & \\
\hline \multirow{2}{*}{ Family Hx of HPN } & Yes & $112(61.9 \%)$ & $76(40.4 \%)$ & $0.418(0.275-0.635)$ & $2.052(1.254-3.360) *$ & .004 \\
\hline & No & $69(38.1 \%)$ & $12(59.6 \%)$ & 1 & 1 & \\
\hline \multirow{2}{*}{ Residency } & Rural & $151(63.2 \%)$ & $88(36.8 \%)$ & $4.1262(0.598-6.555)$ & $0.271(.080-.911) *$ & .035 \\
\hline & Urban & $126(29.4 \%)$ & $89(70.6 \%)$ & 1 & 1 & $<=0.001$ \\
\hline \multirow{2}{*}{ Education } & No formal & $10(5.3 \%)$ & $48(26.5 \%)$ & $0.294(0.154-.558)$ & $3.924(1.636-9.412) *$ & .002 \\
\hline & Secondary + & $113(60.1 \%)$ & $80(44.2 \%)$ & 1 & 1 & .004 \\
\hline
\end{tabular}




\begin{tabular}{|c|c|c|c|c|c|c|}
\hline \multirow{2}{*}{ Variable } & \multirow{2}{*}{ Response } & \multicolumn{2}{|l|}{ Knowledge } & \multirow{2}{*}{ COR $(95 \% \mathrm{CI})$} & \multirow{2}{*}{ AOR $(95 \% C I)$} & \multirow{2}{*}{$P$ value } \\
\hline & & Good & Poor & & & \\
\hline \multirow{4}{*}{ Occupation } & Farmer & $4(2.5 \%)$ & $25(13.8 \%)$ & $0.226(0.083-0.617)$ & $0.271(.080-0.911) *$ & .035 \\
\hline & House wife & $16(8.5 \%)$ & $32(17.7 \%)$ & $0.775(0.409-1.468)$ & $0.775(.345-1.740)$ & .536 \\
\hline & Merchant & $63(33.5 \%)$ & $33(18.2 \%)$ & $1.131(0.694-1.844)$ & $2.848(1.173-6.914)) *$ & .021 \\
\hline & Civil servant & $105(55.9 \%)$ & $91(50.3 \%)$ & 1 & 1 & .001 \\
\hline
\end{tabular}

\subsection{Factors Influencing Self-care Practice Regarding Hypertension}

Bivariate analysis showed significant associations between self-care practice and educational status, habits, place of residence, source of health information, and family history of hypertension, knowledge, and occupation of the respondents. With multiple logistic analyses, only place of residency and educational status of the respondents maintained a significant association with self-care practices of hypertension. Multivariate analysis revealed that there was a statical association between self-care practices and educational status. Study subjects who had primary education approximately three times less likely to have good self-care practice as compared with those who have secondary and above. $\{(\mathrm{p}=0.013$, AOR $(95 \% \mathrm{CI})=2.352(1.196-4.625)\}$. But there was no statical association between self-care practices and no formal education's $\{(\mathrm{P}=0.580$, AOR $(95 \% \mathrm{CI}) 1.223$ (.600-2.493)\}. Study subjects who living in rural three times less likely to have good self- care practices as compared with subjects who live in urban areas $\{(\mathrm{P}=0.000, \mathrm{AOR}$ $(95 \% \mathrm{CI})=2.879(1.757-4.717)$. Table 8

Table 8. Factors affecting self-care practices among hypertensive patients in public hospitals of Addis Ababa City Administration April 2016 Addis Ababa Ethiopia.

\begin{tabular}{|c|c|c|c|c|c|}
\hline \multirow{2}{*}{ Variable } & \multicolumn{2}{|c|}{ Self-care Practice } & \multirow{2}{*}{ COR $(95 \% C I)$} & \multirow{2}{*}{ AOR $(95 \% C I)$} & \multirow{2}{*}{$P$ value } \\
\hline & Poor & Good & & & \\
\hline \multicolumn{6}{|l|}{ residency } \\
\hline Ruler & $108(53.7 \%$ & $133(79.2 \%)$ & $3.272(2.057-5.205)$ & $2.879(1.757-4.717)^{* * *}$ & .001 \\
\hline Urban & $93(46.3 \%)$ & $35(20.8 \%)$ & 1 & 1 & $<=0.001$ \\
\hline \multicolumn{6}{|l|}{ Educational status } \\
\hline No formal education & $42(20.9 \%)$ & $16(9.5 \%)$ & $0.294(0.154-0.558)$ & $(1.223(.600-2.493)$ & 0.580 \\
\hline Primary & $75(37.3 \%)$ & $43(25.6 \%)$ & $0.442(0.276-0.707)$ & $2.352(1.196-4.625) *$ & 0.013 \\
\hline Secondary and above & $84(41.8 \%)$ & $109(64.9 \%)$ & 1 & 1 & 0.005 \\
\hline
\end{tabular}

${ }^{*} \mathrm{p}<0.05 * * \mathrm{p}<0.01 * * * \mathrm{p}<0.001$

\section{Discussion}

This study was conducted with the intention to assessing level knowledge, self-care practices and associated factors among hypertensive patients in public hospitals of Addis Ababa City administration. The study showed that the mean $( \pm$ SD) knowledge score of the study participants was 15.0325 ( \pm 2.98$)$. In this study out Of the 369 study participants, 181 (49.1\%) and 201 (54.5\%) had poor knowledge and poor self-care practices towards hypertension, respectively. This is low when compared to studies in West Indies and Malaysia. (18, 27, 32), but high compared with study in another part of Pakistan.[20] The low score of knowledge and self-care practice was mainly due to illiteracy and low socioeconomic class of the patients Participants with poor practice scores had poor control on blood pressure. The common reasons for poor practice were mainly poor compliance, lack of regular follow-up, poor diet control, and lack of physical exercise of the 181 study subjects who had a family history of hypertension about $112(59.6 \%)$ had good knowledge. from those who had good knowledge about hypertension 80 (44.2\%) of the study subjects attended at least secondary school. This is inlined with a study conducted in Ghana in which subjects with master's degree and above have good knowledge as compared to less educated. (36). In fact, 186 (50.4\%) of hypertensive respondents acknowledged that they received knowledge from their health professionals. This is similar to the study conducted in China [30].

This study ascertained that the majority of the study participants had good knowledge about hypertension definition, risk factors, exercise, diet, and signs and symptoms, but poor knowledge about the particular exercise, duration of exercise, food contents to avoid, stress reduction techniques, diagnostic techniques, and evidence of target organ damage. This approximately Similar to studies done in Nepal, sub-Sahara Nigeria, and India.]. A study done in Pakistan revealed that a large number of participants considered salt intake as a risk factor to be associated with high BP. This is different from our study in the great majority of the respondents responded that age is the major risk factor for high blood pressure. This may be due to differences in educational status [41].

Alarmingly, very high numbers of 173 (46.95) study subjects defined hypertension as blood pressure greater than or equal to $140 / 90 \mathrm{mmHg}$, whereas the rest $132(35.8 \%)$ and $64(17.8 \%)$ of the respondents responded that I do not know and call numbers that are less than 140/90 $\mathrm{mmHg}$, respectively. This is high compared with a study conducted in Pakistan in which only (8\%) were aware of the correct definition of HTN, and the majority of the patients $(82 \%)$ did not know anything about this term (42). For the signs 
and symptoms of hypertension, it was observed that the majority of the participants $(n=369 ; 92.1 \%$ mentioned that hypertension had several signs and symptoms. Some of the signs and symptoms identified included headache, dizziness, and nausea. This is high compared to other studies in other areas. This may be due to the difference in the educational status of the participants [42]. This study revealed that almost half $(49.1 \%)$ of the study participants had a family history of hypertension. Respondents who had no family history of hypertension two times less likely to have good knowledge about hypertension compared with those who had a family history of the disease $(\mathrm{p}=0.004$, AOR (95\%CI) 2.052 (1.254-3.360). This finding is in agreement with the study in Botswana, that revealed the level of knowledge related to hypertension was high in participants who had a family history of hypertension (28). This study ascertained that there is statistical association between self-care practices and educational status and place of residence on multivariant logistic regression. Study subjects who had primary educational level approximately three times less likely to have good self-care practice as compared with those who had secondary and above educational level. $\{(\mathrm{p}=0.013$, AOR $(95 \% \mathrm{CI})=2.352$ (1.196$4.625)\}$. But there was no statistical association between self-care practice and no formal education's $\{(\mathrm{P}=0.580$, AOR $(95 \% \mathrm{CI}) 1.223(.600-2.493)\}$. These findings are in agreement with other studies that demonstrated education is regarded as an essential prerequisite for self-care practices of a chronic disease [39].

In this study, $351(95.1 \%)$ claimed to check their blood pressure regularly with most of them checking monthly, 234 (66.7\%), this is high compared with the study done in Saudi Arabia. This may be due to differences in the educational status of the respondents [41].

Study participants who live in rural three times less likely to have good self- care practice as compared with participants who live in urban area. $\{(\mathrm{P}=0.000, \mathrm{AOR}$ $(95 \% \mathrm{CI})=2.879(1.757-4.717)\}$. this is an inconsistency with the study in Saudi Arabia. This may be due to different social, educational, and economic status [41).

About 204 (55.7\%) participants were involved in regular exercise for at least three times a week. This is low compared to study in Saudi Arabia. This may be due to educational status [39].

Limitations

1. Social desirability bias due to a sensitive and personal question related to knowledge and self-care especially, regarding financial issues.

2. Because the data are cross-sectional, the direction of the causal relationship between variables can't always be determined.

\section{Conclusion and Recommendations}

\subsection{Conclusion}

Despite the important role of knowledge and self-care practices in the management of hypertension were recognized to be useful and effective in achieving hypertension control and preventing its complication, the findings of this study confirmed previous findings concerning self-care among people with self-care practice was accomplished as recommended by majority respondents but knowledge was more problematic. The self-care practice diet management practices, exercise, blood pressure checkup, away from habit especially, warrants. However, regular checkups of blood pressure and diet management practice are said to be the cornerstone of self-care practices and a hypertension control. Generally, self-care practices were suboptimal among hypertensive patients in public hospitals of Addis Ababa City administration.

\subsection{Recommendation}

Family members should be informed about their important roles in encouraging patients to undergo a hypertension control or self-care practices.

Healthcare personnel must increase patient's awareness of the importance of all types of self-care practices domains and strongly promote the practice among hypertensive patients via strengthening the IEC program, and the hypertension association.

Staff members of the rental units and department of internal medicine need to participate in strengthening the overall awareness of the patients toward their self-care practice.

Nursing research should be carried out to investigate knowledge and self-care in a broader social context and larger sample size.

All nurses' workings on hypertension should give strict advice on the importance of self-care practices for hypertensive patients during their follow- up schedule and develop educational programs and activities to educate patients on the prevention and treatment of hypertension, and should not rely on medical intervention only.

Ethical Approval and Consent to Participate

This study was carried out after getting ethical clearance from the Addis Ababa University research ethics review committee. Data collection was carried out after receiving an ethical clearance letter from the town administrative health bureau. Informed written consent was obtained from each respondents prior to data collection.

\section{List Acronyms and Abbreviations}

$\begin{array}{ll}\text { AAU } & \text { Addis Ababa University } \\ \text { BP } & \text { Blood Pressure } \\ \text { CHD } & \text { Coronary Heart Disease } \\ \text { CHF } & \text { Congestive Heart Failure } \\ \text { CI } & \text { Confidence Interval } \\ \text { CVD } & \text { Cardio Vascular disease } \\ \text { DBP } & \text { Diastolic Blood Pressure } \\ \text { HPN } & \text { Hypertension } \\ \text { SD } & \text { Standard Deviation } \\ \text { SBP } & \text { Systolic Blood Pressure }\end{array}$


SMBP self-monitoring blood pressure

SPSS Statistical Package for Social Science Research

TV Television

UN United Nations

WHO World Health Organization

\section{Consent for Publication}

Not applicable

\section{Availability of Data}

The datasets used and/or analyzed during the current study available from the corresponding authors on reasonable request.

\section{Author's Contribution}

Sindew Mahmud: contributions to the study protocol design development, data collection, data quality monitoring, data analysis, and preparation of the manuscript.

Melaku Belay Tefri: contributions to the study protocol design development, data collection, data quality monitoring, data analysis, and preparation of the manuscript.

\section{Conflict of Interest}

The authors declare that we do not have any financial or non-financial competing interests in reference to this article for its publication.

\section{Funding Statement}

Not applicable.

\section{Acknowledgements}

We would like to thanks to town administrative health office heads for their collaboration during conducting this research. At last but not least, we would like to forward our special thank and sincere appreciation to our friends who gave advice and comments throughout the entire research project activities.

\section{References}

[1] Alsolami F, Hou X, Correa-Velez I. Factors Affecting Antihypertensive Treatment Adherence: A Saudi Arabian Perspective. Clin Med Diagnostics. 2012; 2: 27-32.

[2] Niman ET, S/O Sreedharan et, edathumtharamal (h), koorachund po, calicut dt k, s. b. effectiveness of structured teaching programme on knowledge regarding hypertension and self-care among hypertensive. 2010; 1 .

[3] Talaat mcrae-SA and A. Effect of Counseling on Patients' Adherence Regarding Anti-Hypertensive Therapeutic Regimen. Life Sci J. 2014; 11 (5): 314-35.
[4] ArticNancy M. Albert, Ph. D., CCNS, CHFN, CCRN, NE-le C. Fluid Management Strategies in Heart Failure. Am Assoc Crit Nurses. 2012; 32 (2): 20-33.

[5] Iyalomhe GBS, Iyalomhe SI. Hypertension-related knowledge, attitudes and lifestyle practices among hypertensive patients. J Public Heal Epidemiol. 2010; 2 (July): $71-7$.

[6] Lee R, Ii P, Pharm D, Cardiology BAQ, Karpiuk EL, Pharm $\mathrm{D}$, et al. Cardiac Transplantation Introduction: Brief. Pharmacother Self-Assessment Program, 6th Ed.

[7] Michael EKG, Assegid S. Prevalence of hypertension and its risk factors in southwest Ethiopia: a hospital-based crosssectional survey. Integr Blood Press Control. 2013; (30 July).

[8] Erkoc SB, Isikli B, Metintas S, Kalyoncu C. Hypertension Knowledge-Level Scale (HK-LS): A Study on Development, Validity, and Reliability. Int J Environ Res Public Heal www.mdpi.com/journal/ijerph. 2012; 9: 1018-29.

[9] Boulle A. Knowledge of the hypertensive person regarding prevention strategies for coronary in the subject Health Studies. http://www.biomedcentral.com. 2009; (March).

[10] Behzad Jahani, Ghodratollah Shakerinejad, Khoda Bakh Karami hypertensive patients in ahwaz; based on health. world J pharmaceutics Res. 2015; 4 (5): 109-20.

[11] Huanhuan Hu, Gang Li and Takashi Arao. Prevalence Rates of Self-Care Behaviors and Related Factors in a Rural Hypertension Population, Int J of hypertension. 2013.

[12] Medicine S. Knowledge, Attitudes and Perception of hypertensive patients towards lifestyle modification in controlling hypertension. 2011; (October): 1-61.

[13] Myo Nyein Aung, et A. awareness and knowledge of hypertension in an at-risk population in the Karen ethnic rural community, Thasongyang, Thailand. Int J Gen Med. 2012; 553-61.

[14] Bonnette ET. Self-care and patients with hypertension at primary health care clinics. Am Assoc Crit Nurses. 2012; (November).

[15] Ross S, Walker A, Macleod MJ. Patient compliance in hypertension: the role of illness perceptions and treatment beliefs. Am Assoc Crit Nurses. 2004; 607-13.

[16] Ali M, Beigi B, Zibaeenezhad MJ, Aghasadeghi K, Jokar A, Shekarforoush S, et al. The Effect of Educational Programs on Hypertension Management. Int Cardiovasc Res J. 2014; 8 (5): 94-8.

[17] Markenson D, Ferguson JD, Chameides L, Cassan P, Epstein J, Gonzales L, et al. Part 17 : First Aid 2010 American Heart Association and American Red Cross Guidelines for. J Am Heart Assoc. 2010.

[18] Eugene V, Bourne PA. Hypertensive patients: knowledge, self-care management practices and challenges. J Behav Heal. 2013; 2 (3): 259-68.

[19] Oliveria SA, Chen RS, Mccarthy BD, Davis CC, Hill MN. Hypertension Knowledge, Awareness, and Attitudes in a Hypertensive Population. Am Hear association. 2003; 219-25.

[20] Mahajan H, Kazi Y, Sharma B, Velhal GD. Assessment of KAP, Risk Factors and Associated Co-Morbidities in Hypertensive Patients. J Dent Med Sci. 2012; 1 (2): 6-14. 
[21] Vikneswari A et al. Knowledge of hypertensive patient. Asian J Res Biol Pharm Sci. 2014; 2 (4): 183-8.

[22] Bollu M, Nalluri KK, Prakash AS, Lohith MN. Study of knowledge, attitude, and practice of general population of guntur toward silent killer diseases: hypertension and diabeteS. Asian J Pharm Clin Res. 2015; 8 (4): 4-8.

[23] Abhinand RS, Sams LM. knowledge of self-care management practice among hypertensive patients. Eur J Nurs. 2014; 1 (1): $27-31$.

[24] Abebe SM, Berhane Y, Worku A, Getachew A. Prevalence and Associated Factors of Hypertension: A Crossectional Community Based Study in Northwest Ethiopia. /journal.pone. 2015; 241: 1-11.

[25] NOBLE. Knowledge, attitude and practice of lifestyle modification among hypertensive patients at. Asian J Pharm Clin Res. 2011.

[26] Bilal M, Haseeb A, Lashkerwala SS, Zahid I, Siddiq K, Dar MI, et al. Knowledge, Awareness and Self-Care Practices of Hypertension Among Cardiac Hypertensive Patients. Glob J Heal Sci Vol. 2016; 8 (2).

[27] Rani M, Beth M, Low SY, Chung PY. knowledge on selfblood pressure monitoring (SBPM) among hypertensive patients in selected wards of Hospital Lam Wah Ee, Malaysia. IeJSME. 2012; 6 (2): 43-5.

[28] LI Z. knowledge and lifestyle practices of hypertensive patients attending a primary health care clinic in Botswana Zungu. Asian J Res Biol Pharm Sci.: 1-14.

[29] Buna Bhandari, et al. Awareness of diseases and self-care practice among hypertensive patients. J Nobel Med Coll. 2012; 1 (2): 29-35.

[30] Li X, Ning N, Hao Y, Sun H, Gao L, Jiao M, et al. Health Literacy in Rural Areas of China: Hypertension Knowledge Survey. Int J Environ Res Public Health. 2013; 1125-38.

[31] Article R. Critiques on the Objective Structured Clinical Examination. Rev Artic. Vol. 34: 478-82.

[32] Guddad S, Malaga U, Kasturiba B, Hasabi I. Knowledge and lifestyle factors of hypertensive subjects. Karnataka J Agric Sci, 2. 2012; 25 (3): 0-3.
[33] Oladapo OO, Salako L, Sadiq L, Soyinka K, Falase AO. Knowledge of Hypertension and other Risk Factors for Heart Disease among Yoruba Rural Southwestern Nigerian Population. Br J Med Med Res. 2013; 3 (4): 993-1003.

[34] Tesfaye F, Byass P, Wall S. Population-based prevalence of high blood pressure among adults in Addis Ababa: uncovering a silent epidemic. BMC Cardiovasc Disord. 2009; 10.

[35] Heymann AD, Bs MB, Gross R, Tabenkin H, Porter B, Porath A. Factors Associated with Hypertensive Patients , Compliance with Recommended Lifestyle Behaviors. 2011; 13 (September): 553-7.

[36] Anomie F, Darkwa S. The Knowledge, Attitudes and Lifestyle Practices of Hypertensive Patients in the Cape Coast. J Sci Res Reports. 2015; 8 (December 2014): 1-15.

[37] Chang AK. Factors affecting self-care in elderly patients with hypertension in Korea. bs_bs_banner Int J Nurs Pract 2015; 2015; 21: 584-91.

[38] Awotidebe, T. O., Adedoyin, R. A., Rasaq, W. A., Adeyeye, V. O., Mbada, C. E., Akinola O. T., Otwombe KN. Knowledge, attitude and Practice of Exercise for blood pressure control: A cross-sectional survey. J Exerc Physiother. 2013; 10 (dec): 110 .

[39] Seminary DM, El-shereef EAA, Thubiany MMAL. Hypertensive Patients: Self-Care Management Practices in Al-Taif, KSA. Int J Sci Res. 2015; 4 (12): 1705-14.

[40] Ambaw AD, Alemie GA, Yohannes SMW, Mengesha ZB. Adherence to antihypertensive treatment and associated factors among patients on follow up at University of Gondar Hospital, Northwest Ethiopia. BMC Public Health [Internet]. BioMed Central Ltd; 2012; 12 (1): 1. Available from: http://www.biomedcentral.com/1471-2458/12/1471-2458-12282.

[41] Alessandro R et. al. Hypertension and hypertension-related disease in Mongolia; findings of a national knowledge, attitudes and practices study. Demaio al BMC Public Heal. $2013 ; 1-10$

[42] Guda Tadesse. Knowledge, attitude and practice towards prevention and control of hypertension. 2015; unpublished (June 2015). 